\title{
SUBJETIVISMO RESPONSÁVEL: NECESSIDADE OU OUSADIA NO ESTUDO DA CONTABILIDADE*
}

\author{
Alessandra Hirano Fuji \\ Mestranda em Controladoria e Contabilidade da FEA/USP \\ E-mail: alehirano@ hotmail.com \\ Valmor Slomski \\ Professor Doutor do Depto. de Contabilidade e Atuária da FEA/USP \\ E-mail: valmor@usp.br
}

\section{RESUMO}

O estudo da Teoria da Contabilidade é relevante para os acadêmicos e para aqueles envolvidos em atividades práticas relacionadas com a Contabilidade Aplicada.

Este trabalho focaliza a inadequação de conceitos tradicionais no estudo da contabilidade conservadorismo, objetividade e custo histórico como base de valor- enfatizando a necessidade de mudanças e quebra de paradigmas.

O desenvolvimento deste trabalho mostra a importância do Subjetivismo Responsável, defendido por Sérgio de ludícibus e outros estudiosos e a necessidade de considerar a relevância de aspectos subjetivos para a qualidade da informação no processo decisório e no atual contexto econômico.

Palavras-chave: objetividade, subjetivismo responsável, qualidade da informação, processo decisório.

\section{ABSTRACT}

The study of accounting theory is relevant for academics and for those who are directly involved in practical activities related to applied accounting.

This work focuses on the inappropriateness of traditional concepts in the study of accounting conservatism, objectivity and historic cost as a value base - emphasizing the need for changes and breach of paradigms.

The development of this study shows the importance of "Responsible Subjectivity", defended by Sérgio de ludícibus and other academics, as well as the need to consider the relevance of subjective aspects for information quality in the decision making process and in the present economic context.

Keywords: objectivity, responsible subjectivity, information quality, decision making process.

\footnotetext{
* Os autores agradecem ao Prof. Dr. L. Nelson Carvalho, do EAC/FEA-USP, por suas valiosas contribuições neste artigo.

Recebido em $10.02 .03 \cdot$ Aceito em $23.10 .03 \cdot 2^{\text {a }}$ versão em $03.11 .03 \cdot 3^{\text {a }}$ versão em 19.11 .03
} 


\section{INTRODUÇÃO}

A Contabilidade é um campo do conhecimento que acompanha a humanidade desde os seus primórdios, sendo que o ato de contabilizar eventos é tão antigo quanto a escrita, conforme evidências arqueológicas.

As Ciências Contábeis não possuem caráter meramente contemplativo e não devem se restringir ao campo da chamada "beleza intrínseca", mas voltarse também para propósitos e questões de natureza prática e utilitária.

Houve grandes mudanças sociais, econômicas e políticas ao longo dos séculos, assim como inovações, descobertas e quebra de paradigmas nas diversas áreas do conhecimento científico.

A Contabilidade, ante o cenário de grandes transformações ocorridas na sociedade como um todo, ainda é alicerçada pelo conservadorismo e pela convenção da Objetividade, fundamentando-se nos Princípios Contábeis Geralmente Aceitos.

No campo acadêmico, considerando-se as pesquisas investigativas e a bibliografia especializada (livros, artigos e congressos), verifica-se, entretanto, que houve (e está havendo) evolução do estudo da Contabilidade em termos de qualidade e profundidade, colocando-a entre os mais promissores e avançados campos do conhecimento científico. Constatase, portanto, uma grande defasagem entre a "Contabilidade Acadêmica" do campo científico e a "Contabilidade Aplicada" do campo profissional.

Conforme ressaltam ludícibus e Carvalho (2001, p.02), "Somos, decidida e paradoxalmente, tão ousados e relevantes em nossos trabalhos acadêmicos quanto tão prudentes e conservadores na prática do dia a dia".

O objetivo do presente artigo é destacar a importância do chamado Subjetivismo Responsável e mostrar que alguns conceitos e técnicas tradicionais utilizados na Contabilidade não são mais condizentes ante a atual realidade econômica, constituindo entraves ao pleno atendimento dos objetivos e necessidades dos usuários da informação contábil.

\section{OS OBJETIVOS DA CONTABILIDADE}

Vatter (1963, p. 179), de Berkeley, ao considerar que as pedras fundamentais na construção de uma teoria da Contabilidade eram os objetivos, questionou o enfoque dado aos postulados e princípios, considerados verdades universais. $O$ autor enfatizou a necessidade de fixar uma meta ou finalidade, de forma que os princípios fossem os meios pelos quais os objetivos poderiam ser atingidos.

Nesse contexto, a Associação Americana de Contabilidade produziu, em 1966, um documento intitulado "A Statement of Basic Accounting Theory (Asobat)", no qual a Contabilidade é " ...o processo de identificação, mensuração e comunicação de informação econômica para permitir a realização de julgamentos bem informados e a tomada de decisões por usuários da informação". O Asobat constituiu-se, pois, no primeiro pronunciamento da teoria da Contabilidade a se orientar para o usuário, priorizando os desejos do usuário em comparação aos pontos de vista dos preparadores das demonstrações contábeis embora a idéia da Contabilidade orientada para o usuário não fosse algo recente.

A idéia de a Contabilidade orientar-se para o usuário fora mencionada, por exemplo, por Paton (1922, p.16): "a função da contabilidade e das explicações de princípios e procedimentos contábeis deve ser exposta em termos de necessidades e das finalidades dos proprietários..."

O Asobat teve grande influência nos trabalhos posteriores, como podemos verificar no pronunciamento $n^{\circ} 4$ do APB e no Referencial Conceitual do FASB. A definição de Contabilidade, conforme o pronunciamento $\mathrm{n}^{\circ} 4$ do APB, é "uma atividade de prestação de serviços...(cuja) função é fornecer informações quantitativas, principalmente de natureza financeira, sobre entidades econômicas, e cuja finalidade é permitir a tomada de decisões econômicas". O FASB também reforçou o enfoque pragmático: "a divulgação financeira deve fornecer informações que sejam úteis para investidores e credores atuais e em potencial, bem como para outros usuários que visem a tomada racional de decisões de investimento, crédito e outras semelhantes."

O objetivo científico da Contabilidade, segundo a Resolução CFC n 774, de 16 de dezembro de 1994, manifesta-se na correta apresentação do Patrimônio e na apreensão e análise das causas das suas mutações. Sob o ponto de vista pragmático, a aplicação da Contabilidade a uma determinada Entidade busca prover os usuários com informações econômicas, financeiras e físicas a respeito do Patrimônio da 
Entidade e suas mutações, compreendendo registros, demonstrações, análises, diagnósticos e prognósticos. Uma questão a ser destacada é a diversidade de usuários, cada qual com suas necessidades e interesses específicos, além da dificuldade em se conhecer os modelos de decisão.

Os usuários da Contabilidade, conforme a citada Resolução, podem ser tanto internos como externos, sendo que as informações geradas pela Entidade devem ser amplas e fidedignas, de modo a permitir a avaliação da situação patrimonial, as mutações do Patrimônio e a realização de inferências sobre o futuro.

A importância da informação contábil em atender a uma vasta gama de usuários foi salientada por ludícibus (2000, p.19), para qual o objetivo da Contabilidade é fornecer aos usuários, independentemente de sua natureza, um conjunto básico de informações que considerem, igualmente bem, todos os tipos de usuários, ou seja, construir "um arquivo básico de informação contábil que possa ser utilizado, de forma flexível, por vários usuários, cada um com ênfases diferentes neste ou naquele tipo de informação, neste ou naquele princípio de avaliação, porém extraídos todos os informes do arquivo básico ou 'data base' estabelecido pela Contabilidade".

A função primordial das Demonstrações Contábeis é o fornecimento de informações financeiras úteis para a tomada de decisões econômicas dos usuários, sendo esse o ponto de partida a ser considerado.

\section{OS USUÁRIOS DA INFORMAÇÃO FINANCEIRA E AS CARACTERÍSTICAS QUALITATIVAS DA INFORMAÇÃO}

A Contabilidade deve priorizar o usuário, de forma que as informações financeiras atendam aos seus desejos e necessidades para a tomada de decisões econômicas.

No tocante ao usuário da informação, há pelo menos duas questões relevantes: a existência de usuários heterogêneos, com funções utilidades distintas e, conseqüentemente, o problema de definir o grupo principal de usuários.

ludícibus (2000, p.21) elencou os principais tipos de usuários das informações contábeis e a natureza básica das informações requisitadas:
Usuário da Informação Contábil

a) Acionista minoritário

b) Acionista majoritário ou com grande participação

c) Acionista preferencial

d) Emprestadores em geral

e) Entidades governamentais

f) Empregados em geral, como assalariados

g) Média e Alta Administração
Meta que desejaria maximizar ou tipo de informação mais importante

fluxo regular de dividendos

fluxo de dividendos, valor de mercado da ação, lucro por ação

fluxo de dividendos mínimos ou fixos

geração de fluxos de caixa futuros suficientes para receber de volta o capital mais os juros, com segurança

valor adicionado, produtividade, lucro tributável

fluxo de caixa futuro capaz de assegurar bons aumentos ou manutenção de salários, com segurança; liquidez

retorno sobre o ativo, retorno sobre o patrimônio líquido; situação de liquidez e endividamento confortáveis.
Nesse quadro, constata-se a diversidade de usuários e suas metas, assim como o interesse em fluxos de renda e de caixa futuros, de forma que as demonstrações contábeis são relevantes à medida que possam ser utilizadas como instrumentos de predição sobre eventos ou tendências futuras.

Nas últimas décadas, no âmbito da Contabilidade de Custos, verifica-se que houve uma grande mudança de foco: a função gerencial passou a prevalecer sobre aquela relacionada apenas à mensuração. A preocupação primeira da Contabilidade de Custos, conforme Martins (2001, p.21-22), estava voltada para a resolução de problemas de mensuração monetária de estoques e de resultado.

Dados o desenvolvimento industrial, o crescimento das empresas e o aumento da competitividade, a Contabilidade de Custos passou a ser um instrumento gerencial, com duas funções importantes para os usuários internos: auxílio ao Controle e respaldo às tomadas de Decisão. A atividade de Controle referese ao fornecimento de dados para o estabelecimento de padrões e orçamentos, assim como para o acompanhamento do que foi previsto e do que foi efetivamente realizado. O processo decisório, por sua vez, abrange os aspectos relativos à fixação de preços de 
venda, opção por comprar ou fabricar, estratégias de curto e longo prazo, entre outros.

Segundo Hendriksen e Van Breda (1999, p. 80), o Asobat procurou fugir da dificuldade de determinação dos desejos dos investidores específicos sugerindo que o fornecimento de informação financeira ficasse subordinado a quatro padrões ou critérios. O FASB denominou tais padrões ou critérios como características qualitativas, que são os atributos necessários para tornar úteis as informações.

Nos quadros a seguir, temos um resumo das características qualitativas da informação, propostas pelo Asobat e pelo FASB, através do Statement of Financial Accounting Concepts n ${ }^{\circ}$ 2, de 1980:

\section{Características qualitativas da informação}

\begin{tabular}{|c|c|}
\hline \multicolumn{2}{|r|}{ Asobat } \\
\hline Relevância & $\begin{array}{l}\text { A informação deve ser pertinente ou associada, de maneira útil, a ações que visem a facilitar ou } \\
\text { aos resultados desejados. }\end{array}$ \\
\hline Ausência de viés & Não favorecimento de um grupo específico de usuários. \\
\hline Quantificabilidade & Possibilidade de mensuração, não necessariamente em termos monetários. \\
\hline \multicolumn{2}{|r|}{ FASB } \\
\hline Benefício e custos & A informação deve proporcionar benefícios superiores aos custos. \\
\hline Relevância & $\begin{array}{l}\text { A informação relevante é pertinente à questão analisada. } \\
\text { Valor preditivo, valor como feedback, oportunidade. }\end{array}$ \\
\hline Confiabilidade & $\begin{array}{l}\text { Qualidade que garante que a informação seja razoavelmente livre de erro e viés e represente } \\
\text { fielmente o que visa a apresentar. Fidelidade de representação, verificabilidade e neutralidade. }\end{array}$ \\
\hline \multirow[t]{2}{*}{ Comparabilidade } & $\begin{array}{l}\text { Qualidade que permite identificar semelhanças e diferenças entre dois conjuntos de fenômenos } \\
\text { econômicos. }\end{array}$ \\
\hline & Uniformidade, consistência. \\
\hline Compreensibilidade & A informação deve ser atingir o maior número de usuários. \\
\hline
\end{tabular}

O Asobat fundamentou-se na convenção da Objetividade ao elencar características como verificabilidade e quantificabilidade.

Quanto à definição de um grupo principal de usuários, o FASB priorizou os acionistas, investidores e credores, enfatizando que a divulgação financeira deve ser útil para a tomada de decisões de investimento, concessão de crédito e outras decisões semelhantes.

A análise custo-benefício de informações contábeis, apesar da simplicidade aparente, constitui tarefa extremamente difícil, mormente no que se refere à mensuração: os custos recaem basicamente sobre os preparadores da informação, mas os benefícios atingem tanto os produtores quanto os usuários. Os custos e benefícios distribuem-se amplamente, sendo repassados tanto aos usuários das informações como para os consumidores de bens e serviços.

Tanto o Asobat quanto o FASB enfocaram a questão da relevância da informação, associando-a à pertinência com relação ao assunto analisado.

A informação é relevante quando é pertinente à questão analisada, afetando pelo menos três aspectos: metas (permite que as metas dos usuários sejam atingidas), compreensão (o destinatário da informação compreende o significado pretendido da informação divulgada) e tomada de decisões (a informação facilita a tomada de decisões dos usuários).

O FASB, dentre os três aspectos, enfatizou a relevância para a tomada de decisões, considerando-a como a capacidade da informação em "fazer diferença" numa decisão. Tal diferença é almejada "ajudando os usuários a fazer predições sobre o resultado de eventos passados, presentes e futuros, ou confirmar ou corrigir expectativas anteriores".

A informação, para ser útil, deve ser oportuna, ou seja, estar disponível ao usuário antes de perder sua capacidade de influência. Conforme Hendriksen e Van Breda (1999, p.99), "a oportunidade não garante relevância, mas não é possível haver relevância sem oportunidade".

A relevância é função, portanto, do valor preditivo, valor como feedback e oportunidade. As informações contábeis, para serem relevantes no processo decisório, precisam servir de insumo para o modelo de tomada de decisão. Os modelos de decisão, por sua vez, são complexos, sendo que há falta de 
entendimento da relação entre os dados contábeis e os eventos/objetos que podem ser insumos para os modelos de tomada de decisão, assim como falta de modelos normativos com descrição suficiente dos insumos.

A confiabilidade, conforme definição no SFAC2, é "a qualidade da informação que garante que a informação seja razoavelmente livre de erro e viés e represente fielmente o que visa representar". Uma base de dados confiável deve caracterizar-se pela fidelidade (representação fidedigna da realidade), verificabilidade e neutralidade.

A comparabilidade amplia a utilidade da informação, à medida que permite comparar uma entidade à outra ou comparar a mesma entidade em períodos diferentes. Objetiva facilitar predições e decisões financeiras, sendo que depende da uniformidade e consistência dos dados e informações.

A uniformidade subentende eventos iguais representados de maneira idêntica, de modo a facilitar a comparabilidade entre empresas diferentes. Há críticas quanto à uniformidade estrita ou rígida, à medida que impõe regras e procedimentos, restringindo a liberdade de escolha da administração e inibindo mudanças favoráveis. Os argumentos contrários são que a diversidade de práticas aceitáveis dificultam a comparabilidade e que a liberdade irrestrita da administração em escolher seus métodos podem propiciar manipulação de dados e presença de viés.

A consistência refere-se ao uso dos mesmos procedimentos contábeis por uma dada empresa ou entidade contábil de um período a outro e ao uso de conceitos e procedimentos de mensuração semelhantes para itens afins nas demonstrações de uma empresa, num dado período.

Cabe destacar a importância da compreensibilidade, pois problemas de linguagem e de comunicação podem interferir no pleno entendimento por parte dos usuários das informações contábeis. Segundo pesquisas realizadas no Brasil e nos Estados Unidos, a linguagem contábil e suas terminologias, notadamente nas notas explicativas, não são suficientemente compreensíveis aos usuários, possuindo alcance limitado, com efeitos adversos sobre o processo de análise, interpretação e, conseqüentemente, na otimização de resultados.

\section{A CONVENÇÃO DA OBJETIVIDADE}

O arcabouço conceitual da Contabilidade, considerando-se a primeira metade do século XX, é predominantemente normativo, enfocando as características objetivas das demonstrações contábeis.

A convenção da Objetividade, também chamada de norma ou restrição, influenciou profundamente as normas práticas e a estrutura conceitual da Contabilidade, ao priorizar informações de caráter histórico e verificável, fundamentadas em transações efetivamente ocorridas e em documentos comprobatórios.

A Objetividade, sob a ótica de Hendriksen (1971, p.114), é uma restrição principalmente quanto ao aspecto da mensuração. As mensurações contábeis, para cumprirem o objetivo de fornecer informações relevantes para predições e tomadas de decisão dos usuários, devem apresentar dois aspectos bem definidos: o atributo a ser mensurado e o procedimento de mensuração adequado para a descrição do atributo.

Segundo o autor, a objetividade tem sido conceituada de maneiras diferentes, tais como:

1. mensurações e avaliações de caráter impessoal ou que se configuram fora do pensamento das pessoas que estão realizando;

2. mensurações baseadas no consenso profissional de experts qualificados;

3. mensurações e avaliações baseadas em evidência e documentação verificável;

4. valor da dispersão estatística das mensurações de um atributo, quando efetuadas por vários pesquisadores.

Há vários aspectos, entretanto, que podem interferir na busca da objetividade, que está intimamente relacionada com a verificabilidade.

Na prática, constata-se que não é fácil separar completamente a medida da pessoa que realiza a mensuração, ou seja, crenças e valores do mensurador podem acarretar avaliação subjetiva e presença de viés pessoal. Numa transação, o valor de mercado independe da pessoa do avaliador, mas o avaliador precisa tomar decisões sobre o valor do ativo que é cedido ou recebido. Em síntese: "o valor, como a beleza, está nos olhos de quem julga".

Um consenso profissional de experts qualificados sobre um procedimento ou mensuração não é resultado de um processo totalmente objetivo, 
sendo decorrente de um processo psicossocial de percepção e julgamento, nem sempre suportado por evidências objetivas.

Quanto às mensurações e avaliações baseadas em evidência e documentação verificável, há mais ênfase na evidência do que na mensuração em si. O problema a ser destacado é que, embora a evidência seja verificável, a seleção do critério de evidência como base de mensuração pode ser objeto de viés pessoal.

A verificabilidade, conforme definição da Asobat, é atributo da informação que permite a indivíduos qualificados, trabalhando independentemente um do outro, chegar a medidas ou conclusões essencialmente iguais. Na prática, mesmo que diversos investigadores utilizem o mesmo método de mensuração de um atributo e baseiem suas medidas em evidência semelhante, podem encontrar valores diferentes, dentro de um mesmo intervalo.

O grau de objetividade ou verificabilidade depende, pois, da dispersão dos valores medidos em torno de uma média. Como o verdadeiro valor da média não pode ser determinado, a diferença entre a média estimada e a verdadeira precisa ser calculada com base em julgamento subjetivo. O próprio valor da média pode, muitas vezes, não retratar adequadamente o atributo a ser considerado.

Toda mensuração é, portanto, um processo de aproximação da realidade, sendo que devemos considerar a subjetividade que lhe é inerente. Nesse contexto, podemos inferir que a mensuração do lucro correto deveria consistir na busca de um intervalo, e não de um ponto, como é tradicionalmente realizado.

\section{A PROBLEMÁTICA DA ESTRUTURA CONTÁBIL TRADICIONAL}

A estrutura contábil tradicional, com base em "Princípios Contábeis Geralmente Aceitos”, é conservadora e prioriza valores passados, com foco voltado principalmente para o lucro como base para a distribuição de dividendos e cálculo do imposto de renda.

No Brasil, a Contabilidade é tradicionalmente conhecida e voltada para apenas um de seus campos de especialização - a Contabilidade Tributária - que, embora relevante, atende primordialmente aos interesses do Fisco. A Lei das S/A, por sua vez, volta-se basicamente aos interesses de um dos usuários das informações contábeis: o acionista. Nesse contexto, surgiu o lamentável estereótipo do contador, como sendo o profissional que "apenas preenche formulários", alimentando a falsa imagem de que o alcance da Contabilidade é muito limitado. Uma questão que colocamos é a seguinte: a estrutura contábil tradicional, permite informações realmente úteis e com teor preditivo aos seus usuários?

Hendriksen e Van Breda (1999, p.93) destacam que a principal dificuldade com a ênfase no processo de contabilização e na estrutura convencional de divulgação é que certos termos contábeis, tais como lucro líquido e receita, e mensurações como custo histórico, possuem pouco ou nenhum significado interpretacional no mundo real.

Houve, principalmente nas últimas décadas, grandes transformações no cenário econômico nacional e mundial, acompanhadas por mudanças e inovações tanto no campo tecnológico como em diversos campos do conhecimento científico.

A curva de conhecimento da Contabilidade (17751975), elaborada por Leo Herbert August (1971) e apresentada por Most (1977, p.05), mostra um crescimento exponencial da Contabilidade, mormente a partir de 1950, com influência de várias disciplinas, tais como Economia, Administração, Psicologia, entre outras, reflexos das mudanças advindas das práticas empresariais.

Nesse contexto, houve, sobretudo, mudança das necessidades do mercado e dos agentes econômicos. O investidor atual, importante usuário da informação contábil, assim como a grande maioria dos usuários, não possui interesses voltados para valores históricos ou passados, mas em fluxos de renda e caixa futuros, ou seja, com o caráter preditivo das demonstrações contábeis. A estrutura contábil tradicional, entretanto, tanto sob o ponto de vista acadêmico quanto profissional, não contribui para atender plenamente às necessidades dos usuários ante 0 contexto atual.

\section{O PRINCÍPIO DO CUSTO HISTÓRICO COMO BASE DE VALOR}

A adoção do custo histórico como base de valor constitui um grande reflexo do conservadorismo da Contabilidade, ao se optar por um valor objetivamente verificável (custo original), 
fruto de avaliação objetiva de transações efetivamente ocorridas.

O custo histórico pode ser adequado apenas no momento do registro da transação, mas perde relevância no decorrer do tempo, seja devido à inflação ou a outros fatores, tais como: inovações tecnológicas, obsolescência, alterações no processo produtivo, condições de mercado e ao impairment do ativo.

Um dos Princípios Fundamentais da Contabilidade, conforme a Resolução CFC n ${ }^{\circ} 750$, de 29 de dezembro de 1993, é o registro pelo valor original, sendo que os componentes do patrimônio devem ser registrados pelos valores originais das transações valores de entrada, que se caracterizam como históricos, objetivos e verificáveis.

Houve mudanças na legislação societária, tais como a introdução de critérios de correção monetária e a possibilidade de reavaliações periódicas de grupos do ativo. Com o advento do Plano Real e um cenário econômico com taxas de inflação consideradas desprezíveis, houve abolição da correção monetária, de modo que o princípio do custo histórico como base de valor continua prevalecendo.

Os ativos, conforme definição do FASB, no SFAC 6, "são benefícios econômicos futuros prováveis, obtidos ou controlados por uma dada entidade em conseqüência de transações ou eventos passados". O FASB, assim como diversos estudiosos, enfatizam a característica essencial do ativo, que reside no seu potencial de benefícios futuros.

Um aspecto relevante é que os custos históricos não expressam o valor econômico dos ativos e, mesmo que atualizados, representam, no máximo, o valor de desembolso na data de aquisição dos mesmos.

Para ludícibus e Carvalho (2001, p.07), "como conseqüência do culto primitivo aos custos históricos, surge a falta de ousadia em reconhecer ganhos não realizados", e que "a qualidade da valoração, em Contabilidade, foi prejudicada pela metodologia. Isto foi se enraizando nos hábitos dos contadores, que perderam a ousadia e criatividade originais de apresentar, se não o valor econômico da empresa, pelo menos o patrimônio líquido como resíduo de ativos e passivos avaliados a valor de mercado "
Houve, felizmente, alguns avanços na utilização de custos históricos, como o uso do valor de mercado e do fair value.

O fair value, conforme Hendriksen e Van Breda (1999, p.309), é o valor total sobre o qual os investidores têm direito a um retorno justo.

Segundo os autores, citados acima, o fair value não é uma base de avaliação específica que pode ser aplicada às demonstrações contábeis de forma genérica, dadas as diferenças de posição entre os tribunais e as empresas de utilidade pública. Para o cálculo do fair value, os tribunais defendem a inclusão de todos os fatos pertinentes, incluindo os custos passados prudentes e custo de reprodução, sendo que as empresas de utilidade pública priorizam a inclusão do custo de reposição.

No cenário internacional, crises financeiras de empresas como Barings, Metallgesechafft, Proctor \& Gamble, Daiwa Securities e Orange County, entre outras, mostraram a necessidade de evidenciação, mensuração e reconhecimento de ativos e instrumentos financeiros até então não incluídos no Balanço Patrimonial (off balance sheet).

Nesse contexto, o FASB, através do SFAS 133 "Accounting for Derivatives Instruments and Hedging Activities", considerou o fair value como a "melhor medida de mensuração de instrumentos financeiros e a única medida possível para os derivativos".

O FASB, considerando as características e peculiaridades dos instrumentos financeiros, notadamente os derivativos - alta alavancagem, grande velocidade das operações e complexidade da estrutura financeira dos produtos - impôs o registro contábil de todos os instrumentos financeiros derivativos a fair value.

O fair value, conforme o SFAS 107 -"Disclosure about Fair Value of Financial Instruments", é "o valor pelo qual esse instrumento poderia ser trocado em uma transação corrente entre partes interessadas, que não seja em uma liquidação ou venda forçada". Trata-se de um conceito mais amplo que o valor de mercado, pois caso os preços de mercado não sejam disponíveis, há outras formas de estimálo: com base no preço cotado de um instrumento em condições similares, análise de fluxos de caixa descontado a valor presente, modelos de precificação de opções, entre outros.

O fair value accounting, conforme Pereira (2000, p.14), parece ser a última grande revolução 
da Contabilidade, pois apesar de seus valores não serem completamente verificáveis (são estimados ou cotados a mercado), "são a melhor forma no momento de se retratar a realidade econômica dos itens patrimoniais expostos no balanço das empresas".

O Banco Central do Brasil, desde 31 de dezembro de 1999, prepara e divulga suas demonstrações financeiras com os ativos realizáveis e passivos exigíveis "marcados a mercado", representando os primeiros esforços na busca de um valor justo - 0 fair value.

A Circular 3.068/2001 do Banco Central do Brasil, trata dos critérios para registro e avaliação contábil de títulos e valores mobiliários, sendo que estes devem ser classificados nas seguintes categorias:

I- títulos para negociação (trading);

II- títulos disponíveis para venda (available- forsale);

III- títulos mantidos até o vencimento (held-tomaturity).

Os títulos para negociação (adquiridos com o propósito de serem ativa e freqüentemente negociados) e os títulos disponíveis para venda devem ser ajustados pelo valor de mercado, de acordo com o art. $2^{\circ}$ da referida circular. No caso de títulos para negociação, a valorização/desvalorização deve ser registrada em adequada conta de receita/despesa no período. No caso de títulos disponíveis para a venda, a valorização/desvalorização deve apresentar contrapartida em adequada conta do Patrimônio Líquido.

Os títulos mantidos até o vencimento, por sua vez, devem ser avaliados pelos respectivos custos de aquisição, acrescidos dos rendimentos auferidos, os quais devem impactar o resultado do período.

O normativo, em sua essência, segue o IAS 39, que trata do reconhecimento e mensuração dos instrumentos financeiros. Segundo o IAS 39, todos os ativos e passivos financeiros devem ser reconhecidos no Balanço Patrimonial, incluindo os derivativos, sendo que o fair value recai nos instrumentos financeiros classificados como trading e available-for-sale.

Os instrumentos financeiros derivativos, conforme a Circular 3082/2002 do Banco Central do Brasil, também devem ser registrados segundo o valor de mercado, computando-se a valorização/des valorização em contrapartida à adequada conta de receita/despesa.
A apuração do valor de mercado, tanto para títulos e valores mobiliários como para derivativos, é de responsabilidade da instituição e deve ser estabelecida com base em critérios consistentes e passíveis de verificação, podendo ser considerados como parâmetros:

I- o preço médio de negociação no dia da apuração ou, quando não disponível, o preço médio de negociação no dia útil anterior;

II- o valor líquido provável de realização obtido mediante adoção de técnica ou modelo de precificação;

III- o preço de instrumento financeiro semelhante, levando em consideração, no mínimo, os prazos de pagamento e vencimento, o risco de crédito e a moeda ou indexador.

Em junho de 2002, devido às desvalorizações dos títulos públicos federais no mercado internacional e à marcação a mercado desses fundos, houve perdas nos fundos de investimento em renda fixa, causando impactos nos investidores e até promovendo, num primeiro instante, uma "migração de recursos" para as cadernetas de poupança.

O fair value constitui, essencialmente, uma ruptura do princípio do custo histórico como base de valor e da convenção da objetividade, à medida que há a contabilização de um valor estimado, não necessariamente objetivo.

As demonstrações contábeis com valores históricos possuem, pois, fraco poder preditivo e informacional, não constituindo instrumental adequado para a tomada de decisões dos agentes econômicos.

\section{A SUBJETIVIDADE NO ESTUDO DA CONTABILIDADE}

$\mathrm{O}$ ato de decidir é parte integrante do cotidiano das pessoas, estando presente mesmo nas situações mais simples, como a escolha da roupa que se irá vestir ou da refeição do dia. O processo de escoIha, tal como na Teoria Econômica, implica a opção pela melhor alternativa dentre as disponíveis, considerando-se as limitações e as vantagens e buscando, em suma, a otimização dos recursos.

A tomada de decisão é parte do processo natural da gestão das organizações, sendo uma das 
responsabilidades gerenciais que vão além das funções básicas do processo administrativo - planejar, organizar, dirigir, controlar -contempladas no início da Administração Científica.

Na literatura, as primeiras propostas de modelos decisórios fundamentaram-se, basicamente, no princípio econômico da maximização do uso dos recursos disponíveis, considerando-se a racionalidade como único fator.

A Teoria dos Jogos, proposta por Von Newmann e Morgenstern (1944, p.05) e outros estudos, mostrou, por sua vez, que as características subjetivas do decisor, tais como a preferência e a atitude perante o risco, são de extrema relevância no processo decisório.

Segundo pesquisa bibliográfica realizada por Steiner Neto (1991), apud Antunes e El Hajj (2002, p.03-04), foram identificadas 16 (dezesseis) variáveis que podem influenciar a tomada de decisão, a saber: idade, nível hierárquico, grau de escolaridade, experiência profissional, atitude perante o risco, interesses funcionais, intuição, excesso de confiança, envolvimento pessoal, negócio da empresa, beneficiários da decisão, grupo de trabaIho, forma de apresentação das possibilidades de resultado, complexidade cognitiva, erros de codificação e tempo.

O processo decisório, como podemos constatar, é tão complexo quanto a própria natureza humana, envolvendo uma vasta gama de variáveis e aspectos subjetivos, inclusive psicológicos, não se restringindo meramente à racionalidade e objetividade.

$\mathrm{Na}$ Contabilidade, há estudiosos contemporâneos que defendem a busca de meios de se aproximar mais do conceito de valor, ao invés da permanente ligação aos conceitos de custo e preço, privilegiando conceitos subjetivos em detrimento da objetividade.

Para Guerreiro e Reis (1998, p.03), a objetividade está relacionada com os interesses dos usuários externos da contabilidade e a subjetividade, por outro lado, se impõe no contexto do usuário interno, ou seja, do gestor interno da organização.

A subjetividade considera as expectativas e percepções pessoais dos agentes econômicos na identificação e mensuração de eventos a serem informados na Contabilidade. A mensuração do ativo, sob a ótica da objetividade, privilegia o custo de aquisição, enquanto que na subjetividade busca-se a melhor expressão do valor num determinado contexto. Nesse caso, o valor de uma máquina produtiva se traduziria no seu fluxo de benefícios futuros.

A própria essência do ativo reside na potencialidade de geração de benefícios futuros. A medida de valor de um ativo, conforme o Comitê de Conceitos Contábeis da American Accounting Association (1957) é "a soma dos preços futuros de mercado dos fluxos de serviços a serem obtidos, descontados pela probabilidade de ocorrência e pelo fator juro, a seus valores atuais". Para Martins (1972, p. 104), "Ativo é o futuro resultado econômico que se espera obter de um agente."

Uma questão importante é o tratamento dos ativos intangíveis. Nas últimas décadas, devido às grandes mudanças tecnológicas e crescente importância do conhecimento e do poder da informação, os ativos tangíveis (tais como edifícios e instalações) não são mais os grandes responsáveis pela geração de valor e de riqueza para a entidade. Empresas como a Microsoft e a Coca Cola, por exemplo, possuem um valor de mercado que é mais de cem vezes o valor de seus ativos tangíveis.

A Contabilidade reconhece o registro dos ativos intangíveis específicos, tais como marcas e patentes, mas não enfatiza o reconhecimento de ativos intangíveis economicamente significativos, como o goodwill e o capital intelectual. A falta de reconhecimento se deve, principalmente, ao grau de subjetividade na mensuração desses ativos intangíveis.

Sob a égide da objetividade, a Contabilidade prioriza a documentação formal, evidências materiais e a tangibilidade do objeto passível de mensuração. Conforme ludicibus (2000, p.71), duas empresas que tenham o mesmo goodwill registrado (pela aquisição), mas desenvolvendo esforços bem diferenciados quanto a pesquisa e desenvolvimento, treinamento de executivos, boas relações industriais, entre outros, terão tendências futuras completamente diferentes. Se tais esforços diferenciados não forem evidenciados, haverá o fornecimento de um quadro "injusto", enviesado e não neutro para os usuários.

Dada a importância do tema, uma forma de cálculo do goodwill foi apresentada por Martins (1972, p. 95-100), consistindo, basicamente, na diferença entre o "valor subjetivo da empresa" (metodologia de fluxos de caixa ou lucros descontados) e o valor dos 
ativos líquidos (através da avaliação do valor de mercado de todos os ativos identificáveis, incluindo os ativos intangíveis).

A origem do capital intelectual está relacionada com o surgimento da sociedade do conhecimento ou sociedade pós-capitalista.

Segundo Edvinssom e Malone (1998, p.09), o capital intelectual é a posse de conhecimento, experiência aplicada, tecnologia organizacional, relacionamento de clientes e habilidades profissionais que proporcionam um diferencial à empresa, ou seja, uma vantagem competitiva no mercado. Os autores fazem uma interessante analogia entre a empresa e a árvore, sendo que o capital intelectual da empresa (valor oculto) é o sistema de raízes da árvore, parte invisível, mas fundamental para a sua existência.

As demonstrações contábeis tradicionais e atuais refletem, basicamente, o capital físico e o capital financeiro da empresa, não evidenciando o capital intelectual. A falta de mensuração e reconhecimento do goodwill criado pela empresa e do capital intelectual, "justificados" pela subjetividade envolvida, faz com que a avaliação patrimonial das empresas não reflita, conseqüentemente, a verdadeira situação econômica.

A subjetividade é inerente a todo processo de mensuração, encontra-se presente em diversos aspectos do processo decisório e não deve constituir obstáculo para a precificação e o reconhecimento de ativos devido ao problema da objetividade.

Conforme ludícibus (1998, p.03) enfatiza, veementemente, "temos de ter capacidade de exercer um subjetivismo responsável, aprendermos a lidar com valores..." e "...não nos acomodar, apenas, numa falsa noção de objetividade".

Jreige (1998, p.08), ao tratar da subjetividade do conceito de true and fair view (visão justa e verdadeira) lembra que ludícibus sugere que, "dada a necessidade de poder preditivo das informações contábeis, o consagrado princípio da objetividade deveria, talvez, ser substituído pelo "subjetivismo responsável".

Para Cardoso e Costa Júnior (2002, p. 32), as propostas apresentadas pelo FASB, por intermédio do SFAS 133, que trata do registro contábil dos instrumentos financeiros derivativos, "tornaram latente o seguinte desafio para os profissionais envolvidos com a contabilidade desses instrumentos: a imperiosa busca pelo subjetivismo responsável".
O subjetivismo responsável, no nosso entender, não se reduz apenas a uma ousadia no estudo da Contabilidade, ao se confrontar com a consagrada Objetividade, mas uma resposta à real necessidade de mudanças, ante o contexto atual e em prol da função primordial das demonstrações contábeis: fornecer informações que realmente subsidiem a tomada de decisões dos usuários.

\section{CONSIDERAÇÕES FINAIS}

A função primordial das demonstrações contábeis é prover informações úteis e confiáveis para a tomada de decisão de seus usuários internos e externos. Idealmente, deveria constituir um arquivo-base com informações que pudessem atender aos mais diversos usuários e seus interesses.

As demonstrações contábeis, para atender às reais necessidades dos usuários, devem possuir caráter preditivo, não refletindo apenas fatos passados e retratar, o mais fielmente possível, a realidade econômica das empresas.

A convenção da Objetividade e o conservadorismo norteiam a estrutura contábil vigente, que evidencia apenas fatos passados e enfatiza a verificabilidade $e$ tangibilidade na mensuração de ativos, não reconhecendo ativos de grande significado econômico, como o goodwill criado pela empresa e o capital intelectual.

A subjetividade, por sua vez, está presente em todo processo de mensuração, na classificação dos eventos e na tomada de decisões dos agentes econômicos.

O fair value, conforme os pronunciamentos do FASB, é a melhor medida de mensuração de instrumentos financeiros e a única medida possível para os derivativos. É decorrente da necessidade de evidenciação, mensuração e reconhecimento de ativos e instrumentos financeiros - incluindo as operações "off balance sheef" - tendo em vista as crises financeiras no cenário internacional.

À medida que pressupõe um valor estimado, o fair value caracteriza-se pela subjetividade e constitui uma ruptura do princípio do custo como base de valor e da convenção da objetividade, além da prevalência da essência sobre a forma.

À luz dessas questões, verifica-se a necessidade premente de repensar alguns conceitos e técnicas tradicionais utilizados na Contabilidade, calcados no 
conservadorismo e objetividade, presentes desde a crise de 1929.

Nas últimas décadas, houve grandes transformações econômicas, políticas, sociais, tecnológicas e em diversos ramos do conhecimento científico. Devemos questionar a validade e a adequação desses "paradigmas contábeis", considerando-se a necessidade atual dos usuários das informações contábeis, no tocante à qualidade da informação no processo decisório.
É necessário, portanto, reduzir a defasagem existente entre a Contabilidade Acadêmica - em evolução- e a Contabilidade aplicada, envolta de obsoletismo.

O "subjetivismo responsável", defendido por ludícibus e outros estudiosos, é mais do que uma inovação no estudo da Contabilidade, mas uma necessidade ante a nova realidade econômica, considerando-se as mudanças ocorridas, as exigências e os atuais desafios do mercado.

\section{REFERÊNCIAS BIBLIOGRÁFICAS}

ANTUNES, Maria Thereza Pompa, EL HAJJ, Zaina Said. Aspectos subjetivos da tomada de decisão. Temática Contábil. Boletim IOB, 2002.

BANCO CENTRAL DO BRASIL. Circular 3068, de 08/01/2001: Estabelece critérios para registro e avaliação contábil de títulos e valores mobiliários.

Circular 3082, de 30/01/2002: Estabelece e consolida critérios para registro e avaliação contábil de instrumentos financeiros derivativos.

CARDOZO, Júlio Sérgio de Souza, COSTA JÚNIOR, Jorge Vieira da. Instrumentos derivativos e a contabilidade de risco: a imperiosa busca pelo subjetivismo responsável. Boletim do Ibracon n² 284, São Paulo, jan/fev 2002.

CONSELHO FEDERAL DE CONTABILIDADE. Resolução CFC $n^{\circ} 750$, de 29 de dezembro de 1993: dispõe sobre os princípios fundamentais de Contabilidade.

CONSELHO FEDERAL DE CONTABILIDADE. Resolução CFC $n^{\circ} 774$, de 16 de dezembro de 1994: aprova o apêndice à resolução sobre os princípios fundamentais de Contabilidade.

EDVINSSON, Leif, MALONE, Michael. Capital Intelectual. São Paulo: Makron Books, 1998.

GUERREIRO, Reinaldo, REIS, Ernando Antonio. O Papel da Subjetividade no Contexto da Contabilidade Gerencial. Congresso Brasileiro de Custos, 1998.

IBRACON. Normas Internacionais de Contabilidade 2001.São Paulo: Ibracon, 2002.

IUDíCIBUS, Sérgio de. Teoria da Contabilidade. $6^{\mathrm{a}}$ ed. São Paulo: Atlas, 2000.

A Contabilidade como Sistema de Informação Empresarial (SIE), Boletim do Ibracon, São Paulo: Ibracon, 1998
CARVALHO, L. Nelson.Porque devemos ousar em Contabilidade. Boletim do Ibracon n 276, São Paulo, maio/2001.

HENDRIKSEN, Eldon S. e VAN BREDA, Michael F. Teoria da Contabilidade. $5^{a}$ ed. São Paulo:Atlas, 1999.

HENDRIKSEN, Eldon S. Accounting Theory, 1971.

JREIGE, Elionor Farah. True and Fair View: um entrave ou um impulso para a contabilidade? Caderno de Estudos, São Paulo, FIPECAFI, v.10, n.17, jan/abr 1998.

MARTINS, Eliseu. Contabilidade de Custos. $8^{\mathrm{a}}$ ed. São Paulo:Atlas, 2001

Contribuição à Avaliação do Ativo Intangível. 1972. Tese (Doutorado em Contabilidade) - Faculdade de Economia, Administração e Contabilidade da Universidade de São Paulo, São Paulo.

MOST, Kenneth. Accounting Theory. Ohio: 1977, Grid, Inc.

PATON, W. A Accounting theory. Accounting Series Press, 1922.

PEREIRA, Carlos Daniel Schneider. Uma contribuição para o entendimento do fair value accounting. Revista do Conselho Regional de Contabilidade de São Paulo, São Paulo, Ano VI, n. 11, p. 06-14, mar. 2000.

SFAS 107 - Disclosure about fair value of financial instruments with concentrations of credit risk, 1990.

SFAS 133 - Accounting for derivative instruments and hedging activities.

VATTER, Willian J. Postulates and principles. Journal of Accounting Research, 1963.

VON NEWMANN, John, MORGENSTERN, Oskar. Theory of games and economic behaviour. Princeton: Princeton University Press, 1944. 


\section{BIBLIOGRAFIA COMPLEMENTAR}

DIAS FILHO, José Maria. A linguagem utilizada na evidenciação contábil: uma análise de sua compreensibilidade à luz da teoria da comunicação. Caderno de Estudos, São Paulo, FIPECAFI, julho/dezembro 2000.

DINIZ, Eduardo Henrique. LOPES, Alexsandro Broedel. Contabilidade: dos escândalos à renovação. Revista de Administração de Empresas executivo. Fundação Getúlio Vargas. v.2, n 2, maio/jul 2003.

FIPECAFI - Fundação Instituto de Pesquisas Atuariais e Financeira. CATELLI, Armando. (Coord.) Controladoria - Uma abordagem da Gestão Econômica - GECON. 2. ed. São Paulo: Atlas, 2001.

LOPES, Alexsandro Broedel, CARVALHO, Luis Nelson Guedes. Contabilização das operações com derivativos: uma comparação entre o SFAS 133 e o arcabouço emanado pelo COSIF. Caderno de estudos da FIPECAFI n ${ }^{\circ} 20$, São Paulo, 1999.

SANTOS, Edilene Santana. Objetividade x Relevância: o que o modelo contábil deseja espelhar?, Caderno de Estudos, São Paulo, FIPECAFI, v.10, n18, maio/agosto 1998.

NOTA:

Endereço dos autores:

ALESSANDRA HIRANO FUJI

VALMOR SLOMSKI

Av. Prof. Luciano Gualberto, 908 - FEA "3" - Cidade Universitária São Paulo - SP - 05508-900 